\title{
THE ECCOE APPROACH TO QUALITY REVIEWING ONLINE DESCRIPTIONS OF LEARNING OPPORTUNITIES
}

Deborah Arnold, AUNEGe, France, Alessandra Antonaci, EADTU, Netherlands,

Lisa Marie Blaschke, Baden Wuerttemberg Cooperative State University Heilbronn, Germany, Gérard Casanova, AUNEGe, France, Ada Giannatelli, Politecnico di Milano -

METID Learning Innovation, Italy, Mykolè Lukošienè, Vytautas Magnus University, Lithuania, Ildikó Mázár, Carmen L Padrón-Nápoles, Knowledge Innovation Centre, Malta, Beatriz Sedano Cuevas, Universidad Nacional de Educación a Distancia (UNED), Spain

\section{Abstract}

As learners seek more flexible learning opportunities, and employers become gradually more open to accepting alternative forms of credentials, there is a need to improve the visibility and quality of the online information available about such opportunities. This information includes not only the descriptions of formal and non-formal learning opportunities, from full degree programmes to optional courses and MOOCs, but also the credentials learning opportunities can lead to and by whom these credentials are recognised. The new Europass initiative of the European Union is a major step forward in this respect, offering the possibility to search for both learning and employment opportunities via a platform that will support a variety of different credentials. Building on the Europass Learning Model, the Erasmus+ ECCOE project makes a significant contribution to this future platform, by defining specific quality criteria for evaluating both learning opportunities and their credentials.

This paper describes the methodology applied for the quality review of online descriptions with the ultimate aim of developing a catalogue showcasing learning opportunities that meet the criteria defined by the project. This methodology concerns two levels: (a) the actual process designed and implemented transnationally for the first iteration of over 100 learning opportunity descriptions, and (b) the two PDCA (Plan, Do, Check, Act) quality improvement cycles applied to refining the process itself. The paper also presents the results of this first iteration and formulates recommendations relevant for learning opportunity providers. Future work involving stakeholder consultation is also presented, as are the synergistic interactions between this 
Arnold, D., Antonaci, A., Blaschke, L. M., Casanova, G., Giannatelli, A., Lukošienė, M., Mázár, I., Padrón-Nápoles, C. L., \& Sedano Cuevas, $B$.

The ECCOE Approach to Quality Reviewing Online Descriptions of Learning Opportunities

research and the overall ECCOE project outcomes within the wider context of

European work on Digital Credentials and open, online and flexible learning.

Keywords: Digital credentials, Micro-credentials, Learning Opportunities, Europass, Quality Review

\section{Introduction}

The move towards more flexible models of higher education provision is a growing trend, even if for many higher education institutions (HEIs) this is still in its early stages (Orr et al., 2018). For learners, this translates into a need to access such flexible opportunities as part of a wider approach to Lifelong Learning (Jaldemark, 2020). A reliable system of digital credentials can address this need by helping to bridge non-formal and formal education, such as recognising MOOC certificates within universities. The European Commission is working on the European Digital Credentials Infrastructure which will support the authentication of such digital credentials (European Union, 2018) within the framework of the new Europass, which includes a database of learning opportunities.

The ECCOE project aims to facilitate the endorsement and appropriation of open, online and flexible higher education, and to increase trust in technology-enabled credentials among students, HEIs and employers. To contribute to these goals, the project has conducted a wide-reaching review of Learning Opportunities (LOpps) which lead to digital credentials. The term Learning Opportunities is abbreviated here as LOpps to avoid any confusion with the commonly used acronym LO for Learning Outcomes. Learners and citizens in general need easy access to clear and precise information about such LOpps, including course content, learning modality, assessment methods and the type and level of credential which they can obtain. This quality review of LOpp descriptions is part of the overall ECCOE project activity around building recognition and trust in digital credentials. Related work conducted within the project involves a parallel study of quality criteria for digital credentials themselves, as well as the creation of a Model Credit Recognition Agreement (Read \& Arnold, 2020) to facilitate inter-institutional recognition. Finally, in support of wider European work on the Europass Learning Model (GitHub, 2020), the development of an overarching ECCOE-system will bring these different elements together to meet the needs of all stakeholders concerned, including learners, HEIs and employers.

ECCOE has thus set up a quality review methodology and associated tools for evaluating LOpp descriptions, 109 of which have been processed through transnational collaboration during the first iteration of the quality review presented here. This paper explains the methodology and tools used, then provides a summary of the results obtained through this first review, followed by the implications of these results and the outlining of further work 
Arnold, D., Antonaci, A., Blaschke, L. M., Casanova, G., Giannatelli, A., Lukošienè, M., Mázár, I., Padrón-Nápoles, C. L., \& Sedano Cuevas, $B$.

The ECCOE Approach to Quality Reviewing Online Descriptions of Learning Opportunities

to be undertaken in order to create a showcase Online Catalogue of Learning Opportunities (OCLO).

\section{Methodology}

The overall process consisted of three main phases:

1. Defining relevant LOpp descriptors;

2. Identifying at least 100 LOpps;

3. Evaluating the quality of the LOpp descriptions.

These phases were conducted as part of a carefully designed collaborative process, with attention paid to collective definition of the criteria and the process, and to providing clear instructions for evaluation of the LOpp descriptions.

\section{Phase 1: Defining relevant LOpp descriptors}

The ECCOE partners first defined the main required descriptors with reference to the European Digital Credential Infrastructure (EDCI) data model for LOpps. This entailed:

- Identifying relevant descriptors from the EDCI LOpp model;

- Classifying these descriptions into three categories:

- Essential (=will be displayed in LOpp list, i.e. in a list which displays results from a particular search)

- Important (=will be displayed in LOpp catalogue entry, i.e. the page in the catalogue which provides details about a single LOpp)

- Background (descriptors which are important for searching / retrieving but which don't need to be displayed);

- Cross checking with descriptors external to the EDCI model, in particular course descriptors identified in other activities of the project.

- Internal peer-review and validation, giving rise to version 1 of the ECCOE LOpp data model.

\section{Phase 2: Identifying at least 100 LOpps}

Quantitative: The project target was to analyse at least 100 LOpps in iteration 1 (with a further 100 to be identified in iteration 2).

Qualitative: As the aim of iteration 1 was to test version 1 of the ECCOE LOpp data model, LOpps could be taken from any source which provides an online description of a LOpp (course, module, MOOC or other type of formal or non-formal learning opportunity). 
Arnold, D., Antonaci, A., Blaschke, L. M., Casanova, G., Giannatelli, A., Lukošienė, M., Mázár, I., Padrón-Nápoles, C. L., \& Sedano Cuevas, $B$.

The ECCOE Approach to Quality Reviewing Online Descriptions of Learning Opportunities

The main sources of LOpps were defined as:

1. MOOCs from the major MOOC platforms;

2. Modules/MOOCs/short courses offered by ECCOE partner institutions;

3. Modules offered by institutions/organisations that we know or trust;

4. Other (any module/MOOC etc. with a description online).

Examples of sources used were FutureLearn, MIT Opencourseware, OpenupEd, FUNMOOC, OpenClassrooms, Coursera, edX, Udacity, Udemy, and POK (Polimi Open Knowledge) as well as institutional offerings at UNED, UOC, VMU, DHBW, and LOpps offered or collected by other Erasmus+ projects, namely eLene4Life and OpenVM.

\section{Phase 3: Evaluating the quality of LOpp descriptions}

The process itself was subjected to two cycles of the Deming PDCA (Plan, Do, Check, Act) wheel (Sokovic et al., 2010). This process involved defining objectives for the activity, outlining the criteria for selecting and evaluating the Learning Opportunities and running at least 20 LOpps through the process before checking the process and results. Questions addressed included: Is the process clear to everyone involved? Is the process itself producing meaningful results? (i.e., is it helping to meet the objectives defined for the activity?). After this initial evaluation, which was conducted collaboratively during a focused online meeting of the ECCOE LOpp task force, any required adjustments were made to the process and tool and were validated collectively before continuing.

\section{The process in detail}

The aim of this activity was to review the LOpps identified in the first iteration against the descriptors defined as required fields. The activity was divided into two steps: content analysis and technical analysis. For reasons of space restrictions, this paper is limited to the presentation of the content analysis.

\section{Content analysis}

In the content analysis there were two types of descriptor. The first type concerned fields where it was simply necessary to establish whether the information relative to this descriptor was present on the LOpp description page on the native (or host) platforms. For these descriptor types the answer was a binary YES or NO. The second type were fields which are frequently completed as free text, so where a more nuanced qualitative evaluation is required. The choices here were: YES (the information is present and of satisfactory quality); INSUF (the information is present but insufficient in quantity/quality or both); and NO (the information is not present). 
Arnold, D., Antonaci, A., Blaschke, L. M., Casanova, G., Giannatelli, A., Lukošienè, M., Mázár, I., Padrón-Nápoles, C. L., \& Sedano Cuevas, $B$.

The ECCOE Approach to Quality Reviewing Online Descriptions of Learning Opportunities

\section{Technical analysis}

During the technical analysis, project team members identified the presence or not of the background information (i.e. data fields required to fully describe a LOpp in the ECCOE showcase catalogue, but which may not be clearly visible in the LOpp descriptions on their native platforms). The choices here were: YES (present and easy to find); YES-BUT (available but difficult to find); and NO (information not available or not found).

\section{Distribution of LOpps among partners}

Each partner reviewed LOpps in their own native language. LOpps in English were distributed among partners, and, in the case of several LOpps coming from the same provider (e.g. FutureLearn or POK), efforts were made to ensure that these were analysed by different partners.

\section{Criteria for initial evaluation of LOpps}

In iteration 1, our aim was to gain an overall picture of how LOpps are described on different platforms and to determine whether there were differences between the different types of providers (MOOC platforms, HEIs).

\section{Ranking and selection of results}

To support the classification and selection, a weighting system was implemented (Table 1). This weighting system measured descriptors on a scale of 3 to 1 , where 3 indicated information a learner absolutely needs in order to know if a LOpp is interesting/relevant for them; 2 represented information which would be useful (but not absolutely necessary) for a learner to consider enrolling; and 1 implied information which would be nice to have, but that many LOpp descriptions don’t (yet) provide. 
Arnold, D., Antonaci, A., Blaschke, L. M., Casanova, G., Giannatelli, A., Lukošienè, M., Mázár, I., Padrón-Nápoles, C. L., \& Sedano Cuevas, $B$.

The ECCOE Approach to Quality Reviewing Online Descriptions of Learning Opportunities

Table 1: Descriptors and weightings

\begin{tabular}{|c|c|c|}
\hline 3: Weighting & 2: Weighting & 1: Weighting \\
\hline $\begin{array}{l}\text { - Description } \\
\text { - } \quad \text { Discipline / subject area } \\
\text { (which can also include } \\
\text { transversal courses) } \\
\text { - Description of learning } \\
\text { - } \quad \text { outcomes } \\
\text { - } \\
\text { - } \text { Assessmequirements } \\
\text { - Type of credential }\end{array}$ & $\begin{array}{ll}\text { - } & \text { Name of provider } \\
\text { - } & \text { Type of provider } \\
\text { - } & \text { Type of LOpp (e.g. } \\
& \text { degree programme, } \\
& \text { course, module, MOOC) } \\
\text { - } \quad \text { Language of } & \text { instruction } \\
\text { - } \quad \text { Level (e.g., beginner, } \\
\text { intermediate, advanced } \\
\text { - } \quad \text { or similar) } \\
\text { - } \quad \text { ECTS of learning } \\
\text { - Start date (including } \\
\text { - } \quad \text { any start date) } \\
\text { - } \quad \text { Woration } \\
\text { - } \quad \text { Admissions procedure } \\
\text { - } \quad \text { Fees }\end{array}$ & $\begin{array}{ll}\text { - } & \text { European } \\
& \text { Qualifications } \\
& \text { Framework (EQF) level } \\
\text { - } & \text { National Qualifications } \\
& \text { Framework (NQF) level } \\
\text { - } & \text { Learning schedule } \\
\text { - } & \text { Activities }\end{array}$ \\
\hline
\end{tabular}

In addition to these, the descriptor "Hosted by" was also weighted as 1 as it is only relevant for MOOCs. Descriptors that concerned standard information (title, URL, contact details, etc.) were not taken into account.

\section{Results}

In total, 133 LOpps were identified. Of these LOpps, 109 were evaluated, and 24 were eliminated as they were either not available at the time of the analysis (e.g., MOOCs no longer running, URL no longer valid), or were not available in a language understandable to any of the partners. Of the 109 LOpps evaluated, there were:

- 60 MOOCs offered by MOOC providers, HEIs, and European projects;

- 29 courses and modules offered by HEIs, including open universities;

- 20 other offered by national and regional consortia, private providers, and nonMOOC offerings by European projects.

\section{MOOC offerings}

After application of the weighting, the scores for MOOC offerings ranged from 47 to 9 (median value of 36 and average of 32). The highest possible score a LOpp could have is 51. Table 2 shows the list of MOOC offerings for the top 20 entries (one third of the overall total). 
Arnold, D., Antonaci, A., Blaschke, L. M., Casanova, G., Giannatelli, A., Lukošienè, M., Mázár, I., Padrón-Nápoles, C. L., \& Sedano Cuevas, $B$.

The ECCOE Approach to Quality Reviewing Online Descriptions of Learning Opportunities

Table 2: $\quad$ Top 20 MOOC Descriptions

\begin{tabular}{llc}
\hline Provider & Title & Score \\
\hline FutureLearn & Veterinary Practitioners and the Food Supply Chain & 47 \\
OpenClassrooms & Improve your presentation skills & 47 \\
FutureLearn & Digital Photography: Creating a Professional Portfolio & 45 \\
FutureLearn & Online Teaching: Creating Courses for Adult Learners & 44 \\
FutureLearn & Microcredential in Business Management- Change Management & 43 \\
FutureLearn & Practical Project Management & 43 \\
UNED Abierta & Starting to write English with no mistakes: level B1 & 43 \\
FutureLearn & Global Development in Practice: Designing an Intervention & 42 \\
Coursera & Know Thyself - The Value and Limits of Self-Knowledge: The & 41 \\
& Examined Life & 41 \\
FutureLearn & Introduction to Management and Leadership in Health Services & 41 \\
MyMOOC & Mixité dans les métiers du numérique & 40 \\
FutureLearn & Financial Analysis and Decision Making with Xero and Tableau & 40 \\
FutureLearn & FinTech - Financial Innovation & 40 \\
MyMOOC & Bien-Etre au travail & 40 \\
MyMOOC & Teambuilding essentials & 40 \\
POK & Entrepreneurs without borders & 40 \\
POK & Gestire il cambiamento & 40 \\
POK & Gestire il confitto & 39 \\
Coursera & Teamwork Skills: Communicating Effectively in Groups & 39 \\
edX & Introduction to Online and Blended Teaching & \\
\hline
\end{tabular}

From Table 2, we can draw a general conclusion that the courses offered on MOOCs platforms were generally well described, as offerings from FutureLearn, MyMOOC, POK, Coursera, OpenClassrooms, UNED Abierta and edX comprise the top 20. The cut-off point for this top 20 was a score of 39. Below this, around half of the remaining MOOC LOpps had scores in the 30-38 range, with a further half in the 9-29 range.

The analysis was also supported by qualitative comments, two examples of which are provided below:

Veterinary Practitioners and the Food Supply Chain:

"Level is postgraduate. Uses Common Microcredentials Framework (CMF). Admissions procedure and entry requirements are vaguely described in the FAQ; need to register with an account to get specifics (I think). Language of instruction seems to be only English (no other languages specified). UK credits: ECTS explained in FAQ." (FutureLearn, 2020)

Learn how to learn:

"Short intros in the list of courses have EQF and NQF levels where they are applicable, although not in this specific case. The levels used on this platform are Easy, Medium and Hard. Learners can build their own schedule and 
Arnold, D., Antonaci, A., Blaschke, L. M., Casanova, G., Giannatelli, A., Lukošienè, M., Mázár, I., Padrón-Nápoles, C. L., \& Sedano Cuevas, $B$.

The ECCOE Approach to Quality Reviewing Online Descriptions of Learning Opportunities

there is guidance on workload depending on level of interest/involvement (very interesting feature)." (OpenClassroom, 2020)

\section{Institutional offerings}

After application of the weighting, the scores of LOpps offered by HEIs ranged from 43 to 5 , with a median value of 26 and average value of 27 (Table 3). If the same cut-off point of 39 is used, only three institutional LOpps would be retained, so instead the top 10 are shown below, representing the same proportion (approximately $1 / 3$ ) as for the MOOCs.

Table 3: $\quad$ Top 10 Institutional LOpp descriptions

\begin{tabular}{llc}
\hline Provider & Title & Score \\
\hline UnivLorraine & Courlis statistique appliquée & 43 \\
UnivDerby_Open & Understandlng Autism, Asperger's and ADHD & 41 \\
UnivCaen & DU Métiers de la Formation et du Développement des Compétences & 40 \\
UnivLorraine & NUMOC & 38 \\
UnivVMU_Open & European Criminal Law and Policy & 37 \\
UnivDerby_Open & GDPR: Data Protection Officer Skills & 36 \\
UnivJyväskylä_Open & Digital Competent Educators & 36 \\
UnivUAB_LLL & Qualification Course for Higher Studies (CQES) & 36 \\
UnivUNED & Simulation models for the design of transition paths towards a & 36 \\
& Sustainable society & 35 \\
\hline
\end{tabular}

To be included in the OCLO, a LOpp must have a YES for all essential descriptors (those weighted at 3), then only eight LOpps are retained, all of which are MOOCs. This represents only $7 \%$ of the LOpps analysed, which is extremely low compared to our initial hypothesis of $20 \%$. Of these eight MOOCs, three are from FutureLearn, two from OpenClassrooms, and one each from FUN-MOOC, OpenCourseworld and OpenVM.

The main criteria which resulted in LOpp exclusion from the OCLO were a) lack of information about learning outcomes and b) lack of indication of discipline. Both criteria to exclude Learning Opportunities in the analysis are extremely relevant. The reason behind the flexibility on assessing the second criterion is the high number of LOpps aiming at developing transversal skills in the analysed set.

\section{Discussion and conclusion}

In this paper we have detailed the methodology developed and applied in order to analyse over 100 online descriptions of Learning Opportunities. The preliminary results show that while some MOOC platforms such as

FutureLearn and Coursera give a highly satisfactory level of information, there is still work to be done in order to provide learners with quality information regarding learning 
Arnold, D., Antonaci, A., Blaschke, L. M., Casanova, G., Giannatelli, A., Lukošienė, M., Mázár, I., Padrón-Nápoles, C. L., \& Sedano Cuevas, $B$.

The ECCOE Approach to Quality Reviewing Online Descriptions of Learning Opportunities

outcomes. However, there is as yet little use of standardised vocabularies, such as the reference to international classification for organising education programmes, and related qualifications by levels and fields for the disciplinary fields (ISCED-F, UNESCO, 2015). Furthermore, competences and learning outcomes are rarely described in reference to standardised vocabularies such as ESCO (European Commission, 2020), the European multilingual classification of Skills/Competences qualifications and Occupations. Furthermore, these standardised vocabularies need to be updated to represent the increasing focus on soft skills. While ESCO does in fact include a whole skills category of soft skills, it is still not widely used by European MOOC providers, nor by European HEIs.

As a consequence, if the ECCOE project wants to reach its objective of developing a showcase catalogue of 60 LOpps, then a series of steps need to be taken before the second iteration. Rather than simply eliminate offerings because they do not meet the inclusion criteria, ECCOE takes a proactive and supportive approach, for example, by providing recommendations for improving LOpp descriptions. An agreement has already been reached with the OpenVM Erasmus+ project, and ECCOE project partners POK (the MOOC platform operated by Politecnico di Milano), Universidad Nacional de Educación a Distancia (UNED) and Vytautas Magnus University (VMU) will also receive recommendations for consideration. A further step is to ensure that the weightings and inclusion criteria are validated by two categories of external stakeholders. First and foremost, by learners and potential learners, and secondly by HEIs and corporate representatives involved in validating credentials. For this latter group, it is necessary to determine whether additional information provided in a LOpp description contributes to reinforcing trust in digital credentials or whether the credential itself is sufficient. Furthermore, it needs to be investigated if the ECCOE LOpp data model is complete, in other words whether existing LOpp descriptions contain additional fields that need to be included.

\section{References}

ECCOE Project. (2020). ECCOE (European Credit Clearinghouse for Opening up Education) Erasmus+ 2019-1-FR01-KA203-062951. Retrieved from https://eccoe.eu/

European Commission. (2020). ESCO. Retrieved from https://ec.europa.eu/esco/portal European Union. (2018). DECISION (EU) 2018/646 OF THE EUROPEAN PARLIAMENT AND OF THE COUNCIL of 18 April 2018 on a common framework for the provision of better services for skills and qualifications (Europass) and repealing Decision No 2241/2004/EC. Official Journal of the European Union. 
Arnold, D., Antonaci, A., Blaschke, L. M., Casanova, G., Giannatelli, A., Lukošienè, M., Mázár, I., Padrón-Nápoles, C. L., \& Sedano Cuevas, $B$.

The ECCOE Approach to Quality Reviewing Online Descriptions of Learning Opportunities

European Union. (2020). About Europass. Retrieved from https://europa.eu/europass/en/about-europass

FutureLearn. (2020). Veterinary Practitioners and the Food Supply Chain. University of Glasgow. Retrieved from https://www.futurelearn.com/microcredentials/vets-andfood-supply-chain

GitHub. (2020). Europass Learning Model. Retrieved from https://github.com/europeancommission-europass/Europass-Learning-Model

Jaldemark, J. (2020). Formal and informal paths of lifelong learning: Hybrid distance educational settings for the digital era. In M. F. Cleveland-Innes \& D. R. Garrison (Eds.), An introduction to distance education: Understanding teaching and learning in a new era ( $2^{\text {nd }}$ ed., pp. 25-42). Routledge. Retrieved from http://urn.kb.se/resolve?urn=urn:nbn:se:miun:diva-37809

OpenClassrooms. (2020). Learn How to Learn. Retrieved from https://openclassrooms.com/en/courses/5281811-learn-how-to-learn

Orr, D., Weller, M., \& Farrow, R. (2018). Models for online, open, flexible and technology enhanced higher education across the globe - a comparative analysis. Retrieved from https://oofat.oerhub.net/OOFAT/

Read, T., \& Arnold, D. (2020). ECCOE: toward a robust solution for the cross-institutional recognition and validation of prior learning. Paper presented at the EDEN Annual Conference, 2020, Timisoara.

Sokovic, M., Pavletic, D., \& Kern Pipan, K. (2010). Quality Improvement Methodologies PDCA Cycle, RADAR Matrix, DMAIC and DFSS. Journal of Achievements in Materials and Manufacturing Engineering, 43(1), 476-483. Retrieved from https://www.researchgate.net/publication/49600834_Quality_improvement_methodo logies_-_PDCA_cycle_RADAR_matrix_DMAIC_and_DFSS

UNESCO. (2015). INTERNATIONAL STANDARD CLASSIFICATION OF EDUCATION - Fields of education and training 2013 (ISCED-F 2013) - Detailed field descriptions. Retrieved from http://uis.unesco.org/sites/default/files/documents/internationalstandard-classification-of-education-fields-of-education-and-training-2013-detailedfield-descriptions-2015-en.pdf 